\title{
An Alternative Model of The ICT Value Creation Process Based on Cross-Impact Analysis
}

\author{
Arnela Ceric \\ Charles Sturt University \\ E-Mail: aceric@csu.edu.au
}

\begin{abstract}
The IT literature has identified several factors influencing business outcomes, also known as ICT (Information Communication Technology) value. In order to make these factors relevant for IT practitioners it is important to classify them in a meaningful and relevant manner. This was done using a systems theory method, crossimpact analysis in analysing the ICT value creation process in three medium-sized organisations. This process is conceptualised as a system of 23 interacting factors. The results of the cross-impact analysis demonstrate that factors have a different functional position in each of the three ICT value creation systems, and hence there are different implications for managing them. Based on the comparison of results among the three organisations, an alternative model of the ICT value creation process is proposed. The model offers further insights into the ICT value creation process that are particularly relevant for IT practitioners and IT researchers.
\end{abstract}

Keywords: ICT Value, Factors Influencing ICT Value, Systems Theory, Interactions, Relationships

\section{INTRODUCTION}

Businesses across the world rely on Information Communication Technology ${ }^{1}$ (ICT) to improve their productivity and efficiency, deliver value to customers, and achieve competitive advantage (Grover \& Kohli, 2012; Gregor et al., 2004). A positive relationship between ICT and organisational performance has also been

\footnotetext{
${ }^{1}$ ICT is synonymous with Information Technology (IT) and Information Systems (IS) to reflect modern information communication technologies. ICT and IT are used interchangeably throughout the paper, mainly to reflect the literature that used the terms IT and ICT.
} 
established by researchers (Mithas, Tafti, Bardhan, \& Goh, 2012; Kohli \& Devaraj, 2003). ICT's impact on organisational performance is its ICT value (Kohli \& Grover, 2008; Melville, Kraemer, \& Gurbaxani, 2004). Gregor et al. (2004) identified four aspects of ICT value: informational (access to internal and external information), strategic (creation of competitive advantage), transactional (business efficiency) and transformational ICT effects (expanded capabilities).

However, less is known of the process of ICT value creation that occurs only when ICT synergistically operates with other organisational factors (Nevo \& Wade, 2010; Kohli \& Grover, 2008). In other words, the research methods described in the literature so far have failed to capture the interactions between ICT and other organisational elements. Nor is there a meaningful classification of factors influencing the ICT value creation process. As ICT is a key aspect of business success, understanding this process is of critical importance for providing directions and insights for managing ICT value (Grover \& Kohli, 2012). The aim of this paper is to investigate the process of ICT value creation. To this end, systems theory is used to conceptualise this process as a system, and a cross-impact analysis is then used to capture and analyse interactions among the system's elements in three organisations.

The findings presented in this paper clarify the role of different elements in the process of ICT value creation. Moreover, a meaningful and relevant classification of these elements is presented. This is essential for advancing our understanding of ICT value creation and its management. The comparison of results across the three ICT value creation systems led to the development of an alternative model of the ICT value creation process. This model has important implications for IT practitioners and researchers in terms of creation of ICT value.

This paper is organised as follows. The literature on factors influencing ICT value is explored in order to identify these factors. Systems theory and a conceptual model of an ICT value creation system are discussed next. This is followed by sections on methodology and data analysis. Lastly, the findings are presented, limitations of the study are identified and some concluding remarks are made.

\section{FACTORS INFLUENCING ICT VALUE}

The Information Technology (IT) literature has identified several factors influencing organisational performance: ICT value. For the purposes of reviewing these factors, they are contextualised as technological, individual, organisational and environmental (Melville et al., 2004).

The technological context contains factors that are related to characteristics of ICT applications. Technology is considered as a form of innovation by Rogers (1995) 
who identified five attributes of innovations. Among these, ICT compatibility with existing technologies, and complexity or ICT user friendliness that explains the degree to which ICT is difficult to use, are particularly important for achieving ICT value (Davis, 1989). ICT integration affects the realisation of ICT value, as it reflects compatibility between ICT and business processes (Rajagopal, 2002). Finally, ICT flexibility, that is, ICT openness to adaptations and upgrades is another element of ICT value (Kumar, 2004).

The second group of factors influencing ICT value pertains to users, who are characterised by their cognitive and emotional qualities. Davis et al. (1989) introduced users' 'attitude toward using ICT.' ICT knowledge and skills were emphasised by a number of researchers (e.g., Attewell, 1992; Melville et al., 2004). Users' knowledge of ICT functions and skills in applying these to perform their work activities are important in utilising ICT and achieving ICT value. Lack of ICT knowledge limits ICT value (Melville et al., 2004). However, users can evolve in terms of their ICT use over time whilst they are learning about ICT and adapting to organisational and technological changes (Jasperson, Carter, \& Zmud, 2005).

The third group of factors reflect organisational context and is of particular importance in creating ICT value. Managers' support and commitment to IT is a key factor typically emphasised in the IT literature (Weill \& Olson, 1989; Bassellier, Benbasat, \& Reich, 2003). As managers are in control of resource allocation, reward systems and training (Fichman, 1992), they have a pronounced impact on the creation of ICT value. Business managers' ICT knowledge was cited as another factor (Boynton, Zmud, \& Jacobs, 1994) because such knowledge enables them to support and promote ICT in their organisation (Bassellier et al., 2003). It also facilitates productive collaboration with IT experts, which is a foundation for alignment between ICT and business strategies (Oh \& Pinsonneault, 2007; Kohli \& Grover, 2008). IT support was emphasised in DeLone and McLean's model of IS success (2003). Organisational strategies influence which ICT goals will be pursued, how ICT will be used and consequently how ICT value will be achieved (Tallon et al., 2000).

The fourth and final set of factors is the external environment of the organisation. The environmental group contains factors related to industry characteristics, competitors, customers and suppliers (Porter, 2008).

A summary of this discussion of the factors influencing ICT value is presented in Table 1.

For the sake of clarity, a generic classification of factors into technological, individual, organisational and environmental groups is provided. This classification is merely descriptive and it does not offer additional insights on managing the process of 
ICT value creation. There is a need for more meaningful classification of factors that inform how they influence ICT value. Understanding how these factors interact with one another may provide additional insights into creating differential value that increases an organisation's competitive advantage (Kohli \& Grover, 2008).

\section{SYSTEMS THEORY}

Systems theory originated with Ludwig von Bertalanffy (1972). It is a foundation for cybernetics, chaos theory, complexity, emergence and complex adaptive systems, among others (Spencer, Austin \& Schutte, 2012). It is used in various areas, including human resource development (Spencer et al., 2012), business model innovation (Halecker \& Hartmann, 2013), technology management (McCarthy, 2003), designing information systems requirements (Patel \& Hackney, 2010) and ICT value (Nevo \& Wade, 2010).

Due to differences in research focus, users, and environments, a system is defined loosely as a collection or set of interrelated elements that maintain "integrity via mutual interactions" (von Bertalanffy, 1972, p. 17) and work towards achieving the aim of the system. Following this definition, an ICT value creation process is conceptualised as a system for the purposes of this research. Elements of an ICT value creation system are related to users, technology as well as organisational and environmental contexts. All of them interact and work towards the creation of ICT value.

Systems theory posits that the elements and their behaviours are interdependent (Ackoff, 1971). Each element affects the creation of ICT value, although, no element has an independent effect on it. Thus an ICT value creation system is created and determined by interactions among the system's elements, as depicted in Figure 1. Based on this understanding it seems that the success of a system depends on the synergistic interaction among its elements. Nevo and Wade (2010) highlighted that the interactions among ICT, users and organisational context are the essential mechanism of ICT value creation.

Figure 1 summarises the key understandings of an ICT value creation system based on systems theory. It depicts a generic ICT value creation system: a process through which ICT value is created. It consists of four contexts and related factors as identified in Table 1, and ICT value composed of four groups of ICT effects (Gregor et al., 2004). All factors, that is, elements of the system are interdependent, and each element is both a cause and effect in relation to other elements. Moreover, the system's properties emerge as a result of interactions among the system's elements (Jokela, Karlsudd, \& Östlund, 2008). As these interactions are unique for each system, 
different ICT value creation systems can attain the same result, and systems with similar conditions and starting points may produce different results (Jokela et al., 2008).

Table 1 Factors Influencing ICT Value Identified in The Literature

\begin{tabular}{|c|c|}
\hline Groups of Factors & Factors and Authors \\
\hline Technological & $\begin{array}{l}\text { - } \text { ICT reliability, flexibility and upgradability (Kumar, 2004) } \\
\text { - } \quad \text { System quality, that is, reliability, convenience, ease of use and } \\
\text { functionality of ICT (DeLone \& McLean, 1992) } \\
\text { - } \quad \text { Information quality or ICT output such as accuracy, timeliness } \\
\text { and completeness of information (DeLone \& McLean, 1992) } \\
\text { - } \quad \text { ICT user friendliness (Davis, Bagozzi, \& Warshaw, 1989) } \\
\text { - } \quad \text { ICT compatibility, complexity, observability, trialability and } \\
\text { competitive advantage (Rogers, 1995) } \\
\text { - } \quad \text { ICT integration (Rajagopal, 2002) }\end{array}$ \\
\hline Individual & $\begin{array}{l}\text { - Human capital, expertise and technical and managerial } \\
\text { knowledge (Melville et al., 2004) } \\
\text { - } \quad \text { User' ICT skills and knowledge (Soh \& Markus, 1995) } \\
\text { - } \quad \text { ICT use (Devaraj \& Kohli, 2003) } \\
\text { - } \quad \text { Intention to use ICT, ICT use, user satisfaction with ICT and its } \\
\text { output (Delone, 2003; DeLone \& McLean, 1992) } \\
\text { - Users' attitude towards ICT (Davis, Bagozzi, \& Warshaw, } \\
\text { 1989) } \\
\text { Users' gender, age, and prior experience with technology } \\
\text { (Venkatesh et al., 2003; Lamb \& Kling, 2003) }\end{array}$ \\
\hline Organisational & $\begin{array}{l}\text { - Policies and rules, organisational structure, workplace practices, } \\
\text { organisational culture (Melville et al., 2004) } \\
\text { - Alignment between ICT and business strategies (Chan \& Reich, } \\
\text { 2007; Sabherwal \& Chan, 2001) } \\
\text { - Organisational culture (Galliers, Merali, \& Spearing, 1994) } \\
\text { - IS-Strategy alignment, organizational and process change, } \\
\text { process performance, information sharing, and IT usage (Kohli } \\
\text { \& Grover, 2008) } \\
\text { - IT management, organisational culture (Soh \& Markus, 1995) } \\
\text { - Managers' resource support (Zhu \& Kraemer, 2005) } \\
\text { - IT support available to users (Delone, 2003; DeLone \& } \\
\text { McLean, 1992) } \\
\text { IT training (Sharma \& Yetton, 2007; Davern \& Kauffman, } \\
\text { 2000) }\end{array}$ \\
\hline External Environment & 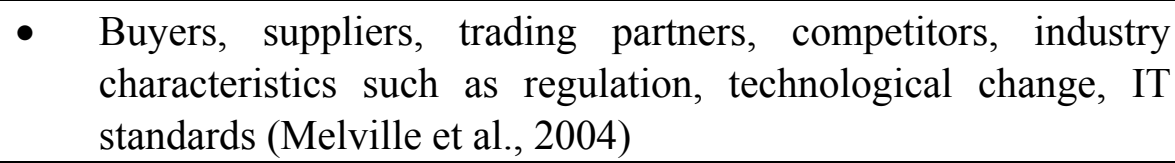 \\
\hline
\end{tabular}




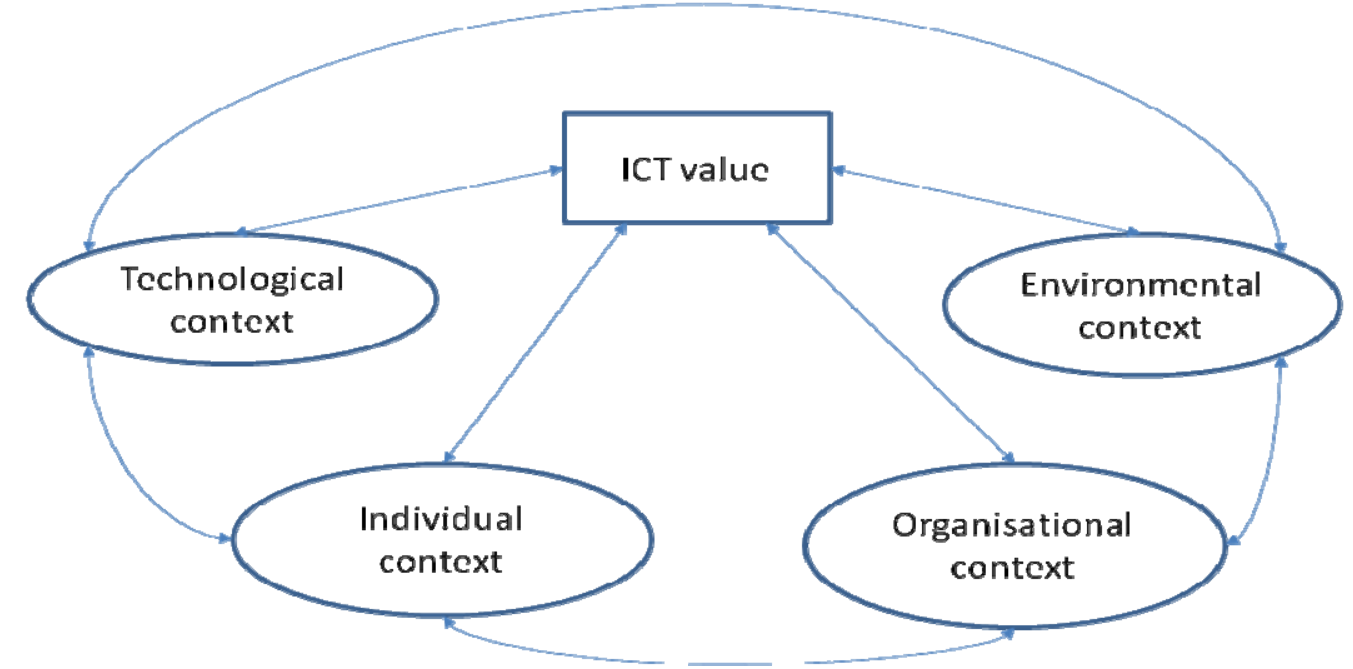

Figure 1 Conceptual Model of an ICT Value Creation System

Based on the foregoing, two propositions can be made.

Proposition 1: The role of each factor in an ICT value creation system will be determined by its collective interactions with other factors in the system.

It is expected that due to differences in organisational objectives, specific ways of functioning and dealing with environmental influences, ICT value creation systems in different organisations will have different interactions among elements. Following the logic expressed in the first proposition, we can state the second proposition:

Proposition 2: A given factor will have a different role in different ICT value creation systems as a result of different interactions in each system.

Consequently, understanding and analysing interactions among the factors are central to understanding the process and outcomes of ICT value creation. For this reason, a systems theory method, cross-impact analysis is used in this research project, as it enables capturing and analysing interactions.

Cross-impact analysis was developed as a forecast scenario method by Helmer (1972) and Gordon and Hayward (1968) in response to shortcomings of the Delphi method (Asan, Bozdağ, \& Polat, 2004). It has since been refined and applied in a range of areas, one of them being IT (Skoko, Ceric and Chun-yan, 2008). Crossimpact analysis emphasises the whole system instead of individual components, and focuses on the purpose for which a system was created, together with that system's interactions, interdependences and relationships among its constituent parts (Messerli, 2000; Schlange, 1995). Cross-impact analysis has three steps (Asan et al., 2004). In the first step, a system and its elements are identified. In the second, relationships among the identified set of factors are assessed in terms of strength and direction of 
each relationship. In the third, interactions among factors are presented visually in a coordinate system, or 'map of interactions'. Then, the map is analysed to assess the important ICT value characteristics of the organisation. The key strength of this method is its analysis of the interactions among the identified set of factors.

\section{METHODOLOGY}

The methodology used in this research represents the three steps of cross-impact analysis. The first stage of the data collection consisted of semi-structured interviews with 53 stakeholders in three organisations with the purpose of identifying factors relevant to the ICT value creation process in each organisation. Content analysis of the transcribed interviews resulted in the identification of 23 factors as representing an ICT value creation system. These correspond to the factors previously reported in the literature review (see Table 1). The identified set of factors was used in the second stage of data collection where IT experts evaluated the interactions among these factors via a survey (see Appendix 1 for further information). IT experts had extensive and comprehensive knowledge of all aspects of the ICT value creation system based on their experience with technology as well as interactions with users and managers. In the third stage, the survey data were analysed by using a set of rules specific to the cross-impact analysis. These rules are discussed later in this section.

\section{Research Context}

This study was conducted in three medium-sized Croatian companies, in response to a call for an international perspective on ICT impact on company performance (Tallon \& Kraemer, 2006). The criterion for choosing the participating companies was the number of years that the company had used ICT. Companies needed to have had a minimum of three years of experience in using ICT applications. This criterion is in line with the understanding that it takes time to develop ICT capabilities, and that realised ICT value can be observed two to three years after ICT implementation (Brynjolfsson, 1993).

\section{Organisation A}

Organisation A was established in 1953 and has 314 employees: 230 in production, and the remaining 84 in management and administration. Organisation A uses the latest ICT applications and exceeds the Croatian industry average in utilising ICT, making it competitive in the European Union (EU) market. Its vision is to continue increasing its competitiveness in the EU market on a solid foundation of investing in technology and people. Its organisational strategies are to manufacture high quality products, reduce operational costs and enhance customer satisfaction. 
Performance is measured in terms of profit and productivity. The role of ICT in achieving the company's strategies is clear: to raise productivity and decrease costs. Without ICT, the company would not be in its dominant market position; indeed the company probably would not have survived.

\section{Organisation B}

Organisation B has 350 employees. Its regional focus since 1943, when it was established, resulted in a monopoly position in the regional market. The perception in the company is that competition has no effect on its operations. In order to complement and support the main business activity (production), it developed two additional business activities: sales and marketing. Separate ICT applications have been developed in each of the three departments. As a result, the newly established IT department is presented with the challenge of integrating ICT applications at the organisational level. Additionally, management failed to invest in updating and integrating technology, as it does not recognise the strategic importance of ICT. Thus, the company's adaptation to market requirements has suffered. Moreover, the key performance indicators are not defined and the goal is simply to perform the required business activities on time.

\section{Organisation C}

Organisation C has been in operation since 1961. It is well situated in the Croatian market and, due to the high quality of its products and well-known brand, it exports its products to other countries. There are 404 employees working in this organisation. The company controls its production process and owns the upstream supply chain. Physical distance between its departments makes ICT very useful. ICT is used to control and connect all business processes, tightly control costs, increase productivity and improve the quality of products. Therefore, in this instance, better ICT means higher productivity, a more competitive position in the market and higher profits. The goal of ICT has been to support and control the entire business process.

\section{Semi-Structured Interviews}

Face-to-face interviews were conducted in a semi-structured format with 53 stakeholders employees, IT experts and senior and top managers in the three organisations (see Appendix 1). The interviewees were chosen through a snowballing strategy. The researcher provided documents on the purpose and background of the research project, as well as the ethics approval and guidelines for interviewees from each organisation. Key organisational stakeholders suggested the appropriate 
interviewees from each department, and provided an office space where interviews took place.

Interview questions were developed based on the review of IT literature to ensure validity of the findings (see Table 1). Interview topics were supplemented by additional issues introduced by interviewees. Interviews were conducted in the Croatian language by the principal researcher. On average each interview lasted for an hour, and it was recorded and transcribed. Based on the content analysis of the transcribed interviews, 23 factors were identified as elements of ICT value creation systems in the three organisations. A few differences were noted among the elements in each organisation. The factor Users' motivation was identified in Organisations A and $\mathrm{C}$, but not in Organisation B. Organisation C differed from the other two organisations in that a specific factor, Collaboration between departments, was identified, but the factor Suppliers was not. Lastly, an additional external factor, Partner organisation, was identified in Organisation B.

\section{Survey}

Factors identified by stakeholders in the three organisations as elements of the ICT value creation system were used in the second stage of the data collection process. A survey was developed with the purpose of assessing strengths and direction of relationships among the identified set of factors. This is done as part of fuzzy cognitive mapping (Asan et al., 2004). The strength of a relationship is based on a fuzzy linguistic scale: strong, medium, weak or no relationship that is represented numerically as 2, 1, 0.5 and 0 (Khoumbati, Themistocleous, \& Irani, 2006). The direction of a relationship can be positive or negative. The direction of a relationship between two factors indicates whether an increase in factor " $X$ " results in increase (positive direction) or decrease in factor "Y" (negative direction) (Kardaras \& Karakostas, 1999).

The survey was presented in the form of a cross-impact matrix, where each factor was presented twice: once in a row, and once in a column. Two cross-impact matrices were used: one for capturing relationships with positive direction, and one for relationships that have negative direction. This strategy allows for clearer understanding of the dynamics of the system. Use of cross-impact matrices enabled systematic assessment of each relationship among the identified set of factors.

IT experts were chosen as survey respondents in each organisation. Justification for choosing IT experts is that they have knowledge of both ICT and organisational context gained through their interactions with users, as well as participating in strategic planning meetings and interacting with senior managers. In addition, they are 
implementing, adapting and maintaining the IT functions to suit the business objectives and organisational specifics. Thus, they were most competent to assess relationships among all factors from different contexts. The survey was conducted with two IT experts in each organisation in the presence of the principal researcher in order to ensure the proper understanding of how relationships are assessed, and to stop the survey process once the respondents showed signs of mental fatigue. Having two IT experts filling out the survey together improved the accuracy of the evaluated interactions as IT experts could discuss and reach an agreement on the value of each interaction. The presence of the researcher improved the clarity and value of this process.

\section{Survey data analysis}

Relationships among the identified set of factors were then analysed using simple mathematical procedures for calculating four indicators for each factor, as indicated in Table 2.

Table 2 Cross-Impact Analysis Indicators

\begin{tabular}{|c|c|c|}
\hline Indicators & Calculation & Explanation \\
\hline Active sum (AS) & $\begin{array}{l}=\text { sum of all influences a } \\
\text { factor exerts on the } \\
\text { system (i.e., sum of } \\
\text { values in each row in the } \\
\text { cross-impact matrix } \\
\left.\left(=\Sigma \mathrm{x}_{\mathrm{i}}\right) .\right)\end{array}$ & $\begin{array}{l}\text { AS is the total effect a cause factor }(\mathrm{X}) \\
\text { has on all effect variables }\left(\mathrm{Y}_{\Sigma \mathrm{i}}\right) \text {. It } \\
\text { indicates the influence that a factor } \\
\text { exerts on the system. }\end{array}$ \\
\hline Passive sum (PS) & $\begin{array}{l}=\text { sum of influences a } \\
\text { factor receives from all } \\
\text { other factors (i.e., sum of } \\
\text { values in each column in } \\
\text { the cross-impact matrix } \\
\left.\left(=\Sigma \mathrm{y}_{\mathrm{i}}\right) .\right)\end{array}$ & $\begin{array}{l}\text { PS is the total effect an effect variable } \\
(\mathrm{Y}) \text { receives from all cause variables } \\
\left(\mathrm{X}_{\Sigma \mathrm{i}}\right) \text {. It indicates the influence that a } \\
\text { factor undergoes in the system. }\end{array}$ \\
\hline $\begin{array}{l}\text { Degree of } \\
\text { interrelation }\end{array}$ & $=\mathrm{AS} * \mathrm{PS}$ & $\begin{array}{l}\text { The higher the degree of interrelation, } \\
\text { the more the factor is integrated with the } \\
\text { system and has more relationships with } \\
\text { other factors, both positive and negative. } \\
\text { As a result, the factor responds to and } \\
\text { spreads the system's influence quickly. }\end{array}$ \\
\hline Degree of activity & $=\mathrm{AS} / \mathrm{PS}$ & $\begin{array}{l}\text { The higher degree of activity, the more } \\
\text { influential the factor is in the system. }\end{array}$ \\
\hline
\end{tabular}


Degree of interrelation (AS*PS) and degree of activity (AS/PS) integrate the active sum (AS) and passive sum (PS) of each factor, and thus provide a cumulative understanding of each factor's influence on and from the system, as well as their interrelationships with other factors in the system. Consequently, these measures reflect each factor's individual role in relation to the overall system and, thus, are used as a starting point for interpretation and classification of each factor.

The degrees of interrelation and of activity are the key indicators that inform the functional position that each factor has in the system. This is presented graphically in a coordinate system, the 'map of interactions', where degree of interrelation is on the vertical axis and degree of activity is on the horizontal axis. Each organisation's map of interactions is presented in Appendix 2. As there are two cross-impact matrices (positive and negative), each factor is represented by two points on the map. For example, factor 14 (IT support) in the map of interactions showing the ICT value creation system in Organisation A (Appendix 2, Figure A2.1) has two components or points, depicted as a circle and a triangle, connected by a line to visually link the pair of points belonging to this factor. A circle represents a stimulating component, and is based on coordinates (i.e., degree of activity and degree of interrelation) from the positive interactions matrix. A triangle presents an inhibiting component and is based on the coordinates from the negative interactions matrix.

The positions of both components of a factor in the map are used to determine the functional position of a factor in the system. This provides important insights into the role that each factor has in the process of ICT value creation. This is the essential contribution of the cross-impact analysis. Based on the specific examples of factors' positions in the three maps of interactions presented in Appendix 2, six main classes of factors are identified, and three of these classes have one more variation with an inhibiting component. This is discussed in the next section.

\section{RESULTS AND DISCUSSION}

The objective of this paper is to explore the application of cross-impact analysis in an ICT value creation context. To this end, three organisations and their ICT value creation systems have been analysed as part of this study. Cross-impact analysis provides a visual representation of a system and its elements in the coordinate system, or map of interactions. This is based on capturing and considering interactions among all elements in a system. Such visual representation is particularly useful for managing ICT value. That is, the position of factors in the map provides important insights for the role that each factor plays in the system. 
Factors in each of the three maps of interactions (see Appendix 2) are found to have similar positions. Based on this notion, these positions are visually summarised and interpreted in Table 3. By understanding the identified positions, factors in each map are classified as levers, critical catalysts, indicators, identity, trends or buffers. Furthermore, indicators, trends and buffers are found to have an inhibiting component. This occurs if their inhibiting point on the map (triangle) has a positive degree of activity (AS/PS $>1)$.

Table 3 classifies factors in each ICT value creation system. It indicates similarities and differences between each ICT value creation system in terms of functional position of its elements, or factors. In addition, it captures a complex situation in each organisation. To illuminate what the table is telling us, and while doing it, we will confirm that it is descriptive; the configuration of buffers with inhibiting potential in Organisation A is used as an example. It has only one buffer with inhibiting potential in common with the other two organisations, and that is Customers. This is a succinct explanation that reflects a more complex situation.

Organisation A has purchased the same information system as its main customer in order to align its production schedule with its customer's production schedule. This is of utmost importance as any delay has significant cost penalty and impact on its reputation. Consequently, the ICT value creation system in Organisation A is organised in such a way as to increase information sharing, collaboration as well as alignment of business processes with the customer. However, such alignment means that relationships with customers also have an inhibiting influence on the ICT value creation system in Organisation A in terms of the direction for its development. Another point emphasised in Table 3 is that factor ICT user friendliness is not a buffer with inhibiting potential in Organisation A, while it is in the other two organisations. This reflects Organisation A's context, and interactions among the elements of its ICT value creation system. ICT user friendliness is found to be a trend in Organisation A. This simply means that this factor is more active in Organisation $A$ than in Organisations B and C. Thus, Table 3 provides a useful description of the complex situation within the three organisations under consideration.

As seen in Table 3, each factor's behaviour and influence on the ICT value creation system can be interpreted based on its position in the map of interactions, that is, its own combination of the degree of interrelation and degree of activity. Based on this understanding, the first proposition can be accepted. This proposition states that the functional role of each factor in an ICT value creation process is determined by its collective interactions with other factors. This is an important finding that implies that management of ICT value needs to consider all factors in the ICT value creation 
process as well as their interactions, rather than a handful of factors randomly chosen that do not represent the whole process and that may introduce perception bias. Such an approach may lead to inaccurate understanding of an ICT value creation system, as well as poor results in creating and managing ICT value.

\section{Table 3 Functional Positions of Factors in The Three Maps of Interactions}

\begin{tabular}{|c|c|c|c|}
\hline $\begin{array}{l}\text { Factor classification and } \\
\text { pictorial representation }\end{array}$ & \multicolumn{3}{|c|}{$\begin{array}{l}\text { Interpretation of factor's position in the map of interaction and } \\
\text { example }\end{array}$} \\
\hline \multirow[t]{2}{*}{$\begin{array}{l}\text { Levers } \\
\text { Stimulation: medium to highly } \\
\text { interrelated and active } \\
\text { Inhibition: weakly interrelated } \\
\text { and passive }\end{array}$} & \multicolumn{3}{|c|}{$\begin{array}{l}\text { Growth of a lever influences growth in many other factors in the system, } \\
\text { without inhibiting factors in the system. For this reason, levers should be } \\
\text { used to influence the system. Influence of highly interrelated levers can } \\
\text { be hard to manage and control. So use levers with medium interrelations } \\
\text { as their influence on the rest of the system will be easier to control. }\end{array}$} \\
\hline & $\begin{array}{l}\text { Organisation A } \\
\text { F14 (IT support) }\end{array}$ & $\begin{array}{l}\text { Organisation B } \\
\text { F13 (IT support) } \\
\text { F10 (Managers's } \\
\text { F11 (Organisatior } \\
\text { strategies) }\end{array}$ & $\begin{array}{l}\text { Organisation C } \\
\text { F14 (IT support) }\end{array}$ \\
\hline
\end{tabular}

Critical catalysts

Stimulation: highly and medium interrelated and active Inhibition: weakly interrelated and active or neutral
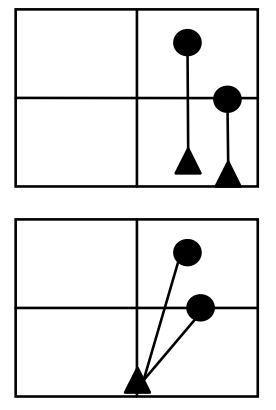

Growth of critical catalysts influences growth of other factors in the system. However, due to its active inhibiting component, a factor in this category also inhibits a few other factors effectively. Growth of critical catalysts will increase their inhibiting component. For this reason, factors in this category must be observed closely.

\begin{tabular}{lll}
\hline Organisation A: & Organisation B: & Organisation C: \\
F11 (Managers' support) & F2 (ICT compatibility) & F1 (ICT integration) \\
F13 (Organisational & F14 (Alignment between & F5 (ICT use) \\
culture) & ICT and organisational & F12 (Organisational \\
F15 (Alignment between & strategies) & strategies) \\
ICT and organisational & & F13 (Organisational \\
strategies) & & culture) \\
& & F18 (Other \\
& & departments) \\
& F20 (Informational \\
& ICT effects)
\end{tabular}

\section{Indicators}

Stimulation: highly and medium interrelated and passive

Inhibition: weakly interrelated and passive

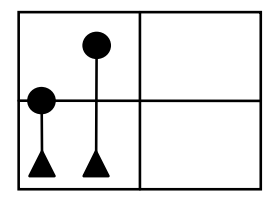

Indicators receive stimulation from other factors of the system, and as a result, they change, thus, indicating changes within the system. These factors can be used to monitor the system. On the other hand, factors in this category are not suitable for interventions into the system, as they are only the symptoms of the larger system.

$\begin{array}{lll}\text { Organisation A: n/a } & \text { Organisation B: } & \text { Organisation C: } \\ & \text { F20 (Informational ICT } & \text { F21 (Strategic ICT } \\ & \text { effects) } & \text { effects) } \\ & \text { F21 (Strategic ICT } & \text { F22 (Transactional } \\ & \text { effects) } & \text { ICT effects) } \\ & \text { F22 (Transactional ICT } & \\ \text { effects) } & \\ & \text { F23 (Transformational } \\ & \\ \text { ICT effects) } & \end{array}$




\section{Table 3 Functional Positions of Factors in The Three Maps of Interactions (Continued)}

\begin{tabular}{|c|c|c|c|}
\hline & \multicolumn{3}{|c|}{$\begin{array}{l}\text { Factors in this category are mainly subject to the influence of the system. } \\
\text { By receiving stimulation from many other factors, they change in ways } \\
\text { that indicate changes within the system. As long as interrelations are } \\
\text { strong, these factors can be used to monitor the system. These factors } \\
\text { also inhibit a few other factors effectively, and their further growth will } \\
\text { increase this inhibiting property. Such influences must be observed } \\
\text { closely when manipulating these factors. }\end{array}$} \\
\hline $\begin{array}{l}\text { inhibiting } \\
\text { hly and } \\
\text { ted and }\end{array}$ & $\begin{array}{l}\text { Organisation A: } \\
\text { F1 (ICT integration) } \\
\text { F2 (ICT compatibility) } \\
\text { F5 (ICT use) } \\
\text { F20 (Informational ICT } \\
\text { effects) }\end{array}$ & $\begin{array}{l}\text { Organisation B: } \\
\text { F1 (ICT integration) } \\
\text { F12 (Organisational } \\
\text { culture) }\end{array}$ & $\begin{array}{l}\text { Organisation C: } \\
\text { F11 (Managers' } \\
\text { support) } \\
\text { F15 (Alignment } \\
\text { between ICT and } \\
\text { organisational } \\
\text { strategies) }\end{array}$ \\
\hline
\end{tabular}

Identity

Stimulation: highly moderately interrelated and neutral (AS/PS=1)

Inhibition: weakly interrelated and neutral $(\mathrm{AS} / \mathrm{PS}=1)$

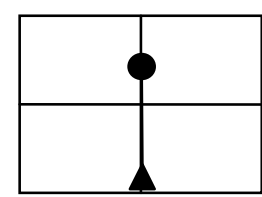

Trends

Stimulation: weakly interrelated and active

Inhibition: weakly interrelated and passive

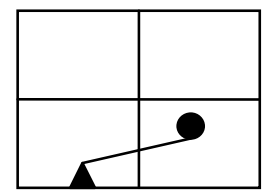

Factors in this category are neutral, that is, they are not active or passive or in influencing the system. As such, they maintain the integrity of the system.

\begin{tabular}{lll}
\hline Organisation A: & Organisation B: n/a & Organisation C: \\
F12 (Organisational & & F2 (ICT \\
strategies) & & compatibility)
\end{tabular}

strategies)

F21 (Strategic ICT

effects)
Trends with inhibiting potential

Stimulation: weakly interrelated and active Inhibition: weakly interrelated and active or neutral

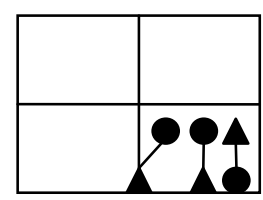

Trends have a stimulating impact on a few other factors. As such they have an impact on the system in the long run. This influence is more visible when the system does not change in that period of time.

\begin{tabular}{lll}
\hline Organisation A: & Organisation B: & Organisation C: \\
F4 (ICT user & F7 (Users' ICT & F7 (Users' \\
friendliness) & knowledge) & motivation) \\
F6 (Users' age and & F15 (ICT seminars) & F23 \\
previous ICT & & (Transformational \\
experience) & & ICT effects)
\end{tabular}

F16 (ICT seminars) 
Table 3 Functional Positions of Factors in The Three Maps of Interactions (Continued)

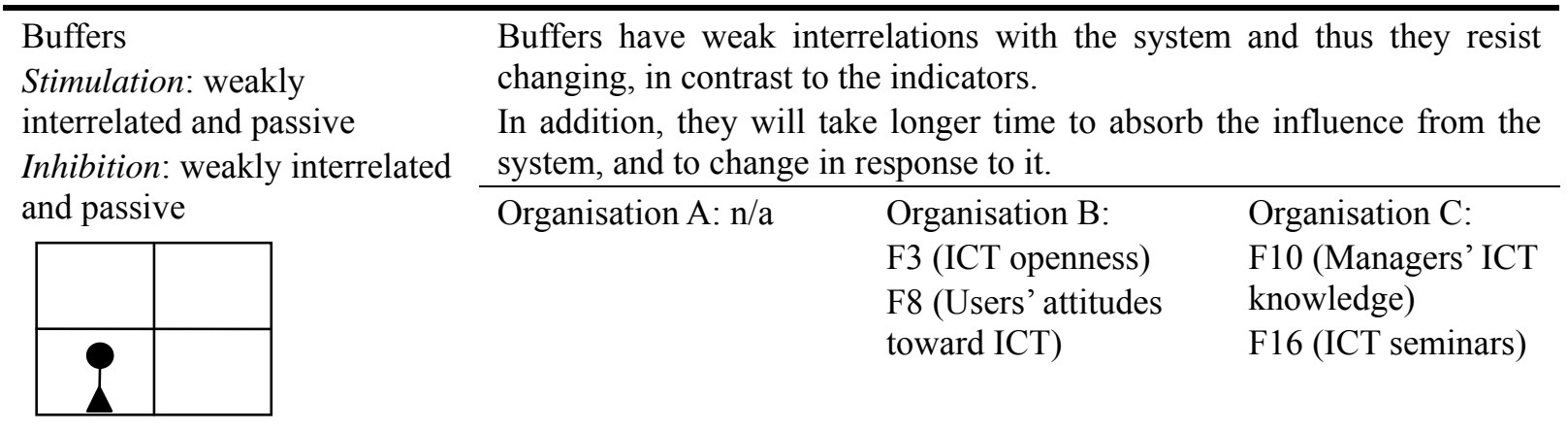

Buffers with inhibiting potential

Stimulation: weakly interrelated and passive Inhibition: weakly interrelated and active or neutral

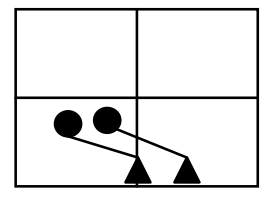

These factors will absorb the influence from the system. On the other hand, they inhibit a few factors in the system. As a result of change in the system, the inhibiting potential of these factors will increase. Thus, they can be seen as inhibiting the change in the system, and for this reason they need to be observed and appropriately managed when the system is changing.

Organisation A:
F7 (Users' motivation)
F8 (Users' ICT
knowledge)
F9 (Users'attitudes
toward ICT)
F17 (Customers)
F22 (Transactional ICT
effects)

Based on the understanding that each factor has a specific functional role in an ICT value creation system, identifying these roles seems beneficial for both practitioners and researchers. Classification of factors in an ICT value creation process does provide meaningful, relevant and applicable insights for managing the ICT value creation process. That is, understanding the functional role of each factor informs practitioners of which strategies to use to create and manage ICT value. On the one hand, focusing on medium and highly interrelated active factors, such as levers and critical catalysts, will produce changes in the system. On the other hand, influencing passive factors will not produce any significant changes or results, as these factors simply absorb the external influences and do not pass much on to the rest of the system. However, they do change as a reaction to the changes in the system. These factors could be used as indicators of change in the system and as an early warning system.

According to Table 3, a majority of factors have different functional roles in each organisation. This means that each organisation used similar resources, but combined 
and integrated them in different ways, resulting in more or less synergy among them, as identified by the strength and direction of relationships among factors in each system. These organisations were not equally effective in organising, maintaining and utilising their ICT value creation systems as a source of competitive advantage.

Three factors were identified as having the same functional role in each organisation. Hence, the second proposition stating that the same factors will have different functional roles in each system is not fully supported. Although the results are different from what was expected, they illustrate an interesting nature of the ICT value creation process. Although each organisation operates in a different industry, uses different strategies to reach its objectives, and has a different structure of ICT value creation, there are similarities between the impacts that certain factors have on each system. This finding is explored next. Factors found to have the same role in each system are identified in Figure 2.

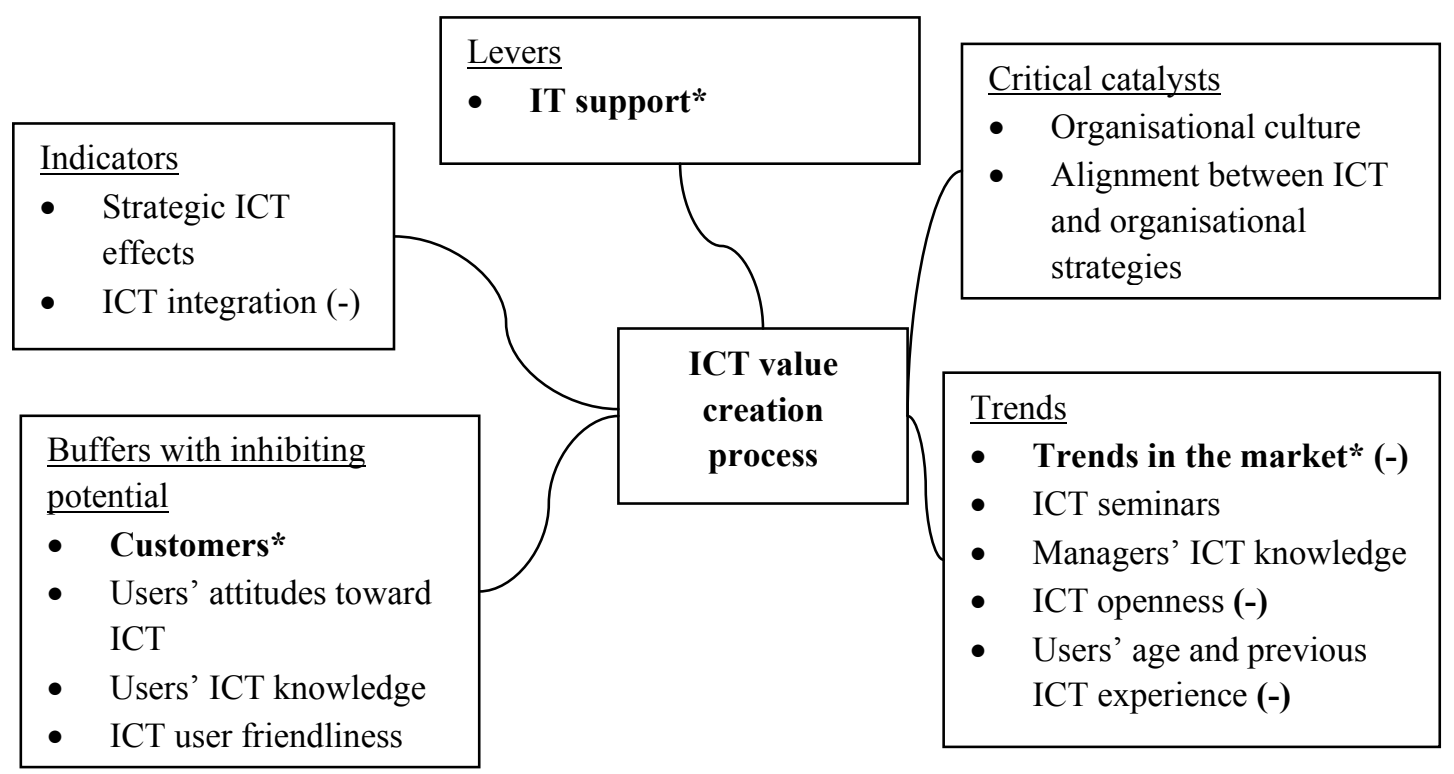

Figure 2 Alternative Model of an ICT Value Creation Process

Note: Symbol '*' identifies factors identified in all three ICT value creation systems; symbol '-, indicates factors with inhibiting potential 
Figure 2 illustrates that three factors have the same role in each of the three ICT value creation systems, and an additional 12 factors are common to any two systems. The model has several insights for understanding the process of ICT value creation.

IT support is of particular importance for creating ICT value. It supports the system's development and it enhances other factors in the system. It participates in shaping ICT utilisation through supporting users, as well as aligning development of ICT functions with organisational strategies. Organisational culture and alignment between IT and organisational strategies also support the ICT value creation process. However, they also inhibit a few other elements in the system. Thus it is important to reflect on these two critical catalysts to understand how they are shaping the system. Any changes in the system triggers change in the two indicators, strategic ICT effects and ICT integration. In other words, the structure of the system determines organisational ability to create competitive advantage and ICT integration with business processes. If there is a discrepancy between the changes in the system and ICT possibilities, ICT integration can suffer, which can inhibit other factors in the system.

Factors that can affect the ICT value creation process over a longer period of time are trends. As organisations need to respond and adapt to market trends, this may affect the ICT value creation process. Providing ICT seminars supports creation of ICT value in the future as it increases users' ICT knowledge and consequently, their ICT use. Managers with ICT knowledge also shape the system over a longer period of time through promoting ICT use and investing into technology. The openness of ICT applications ensures flexibility and adaptability of the system to changing organisational needs. If ICT applications are not open, they may become obsolete or restrict organisational growth. Users' age and previous ICT experience is another source of influence on the system in the long run. If users have difficulties with accepting and learning to use ICT, the system needs to invest additional energy to support them and this can inhibit other elements in the system.

Buffers that are important to consider in value creation process are customers, users' ICT attitudes and knowledge and ICT user friendliness. These factors respond to changes in the system, albeit very slowly. It takes a great deal of effort to change relationships with customers, as well as users' attitudes and ICT knowledge. These factors resist change, and at the same time inhibit a few other elements in the system. For example, users may have only basic ICT knowledge and cannot use additional ICT functions required by the changes in the system. Buffers cannot be changed through direct influence, but through influencing other factors in the system, for example, organisational culture, IT support and even ICT seminars. 


\section{Implications}

The use of cross-impact analysis in the ICT value context resulted in classification of factors based on their positions in the three ICT value creation systems. The proposed classification provides important insights into the process of ICT value creation. It demonstrates that factors have different functional roles in ICT value creation systems. They are classified as levers, critical catalysts, trends, indicators or buffers. Each class of factors has relevant implications for managing and understanding the process of ICT value creation.

Levers and trends are active factors, and they influence the system. In contrast, indicators and buffers are influenced by the system, and they change in response to it. An additional difference between identified classes of factors is their degree of interrelation, that is, the speed with which they influence or are influenced by the system. Levers, critical catalysts and indicators are much faster in influencing and reacting to the system, while the time frame for trends and buffers is much longer. Levers with high degrees of interrelation can influence the system in the short term, and due to the strength and speed of their impact, the resulting change can be difficult to control and manage appropriately. Thus, it is recommended that practitioners use levers with a medium degree of interrelation in order to be able to control and manage the system. At the same time, indicators with a high degree of interrelation are good monitors of any change initiative that is introduced to the system.

Furthermore, IT support was classified as a lever in all three ICT value creation systems, signifying its active and critical role in creating and managing ICT value in each organisation. IT experts are the channel through which organisational ICT goals are transformed into practical actions that are then communicated to users, and used to direct their ICT use. By constant realignment between the changing nature of organisational goals and users' ICT skills, IT experts have a major impact on the system through providing IT support to users, and thereby on the realisation of organisational objectives. Recognising this means that IT managers need to have adequate resources, and can play an important role in strategic decision making.

Next, "trends in the market" have been classified as a trend or trend with an inhibiting potential. Trends introduce changes in the majority of industries and shape organisational strategies, the choice of ICT applications, and ways of using them. Hence, ICT systems need to be responsive and adaptable to trends in the market such as new ICT applications used by competitors, serving customers and meeting their ever changing needs, among others. Flexibility and speed of adaptability of ICT value creation systems will depend on a range of factors, such as the nature of organisational processes and ICT functions and design. Again, IT managers may have an important 
role in ensuring that organisations buy open systems, and that employees are being trained in a range of ICT functions that may be needed to reach organisational goals.

Lastly, customers are classified as a buffer with inhibiting potential. As such, relationships with customers may affect the future success of ICT value creation systems. Organisations like Organisation A that use ICT to establish their partnerships and collaborations with their customers may perceive better results of their ICT value creation systems. However, this may direct the future developments of the system and inhibit the flexibility and adaptability of ICT value creation systems. Finding a balance between ICT developments that serve organisational strategic goals on one hand, and collaboration with customers enabled by compatible technology on the other, is needed.

Classification of factors based on their functional roles suggested in this paper is meaningful, relevant and applicable for practitioners. Based on the proposed classification, practitioners can identify opportunities for creating ICT value, make decisions on the best ways to improve ICT value, and evaluate demands on organisational resources and users.

\section{Limitations of The Study}

The main limitation of the research findings is that they are based on mediumsized organisations, and thus, the findings may not be applicable to small and micro organisations, or to large multinational organisations. Furthermore, the organisations that took part in this research are based in Croatia, so cultural differences may restrict the applicability of the findings to organisations in other countries. Thus, additional research is needed in both small and large organisations, and in different countries to confirm applicability of the ICT value creation model as conceptualised in this paper. Further research is also needed into interactions between factors influencing ICT value and models that capture the dynamics of ICT value creation systems. Systems theory and theories of complexity may play an important role in the future research on ICT business value, as they focus on interrelations and interactions among a set of factors and use these to explain the system's behaviour.

Cross-impact analysis is a case-based method, so the findings related to classification of factors presented in this paper may not be generally applicable. Different ICT value creation systems may have the same elements, but are likely to have different interactions, and consequently, a different constellation of levers, critical catalysts, trends, indicators and buffers of the system. Analysis of several ICT value creation systems would allow identification of factors in common across each dimension of the systems, and would support the generalisation of findings. In 
addition, the last three propositions made based on the findings in this study need to be tested on a larger sample.

\section{CONCLUSION}

Factors affecting the ICT value creation process have previously been identified in the IT literature. However, rarely have factors from technological, individual, organisational, and external environmental contexts been considered together or as a system. The objectives of the study were to demonstrate the application of the crossimpact analysis in the area of ICT value, and to classify the factors that interact with one another in an ICT value creation system based on their functional roles. The findings of the cross-impact analysis support the first proposition stating that each factor has a specific functional role in the ICT value creation process determined by its collective interactions.

Results of the cross-impact analysis demonstrate that each factor's influence on the ICT value creation system can be interpreted based on its position in the map of interactions, that is, its particular combination of the degree of interrelation and degree of activity. That is, the functional role of each factor in an ICT value creation process is determined by its collective interactions with other factors. This finding emphasises the need to take into account the interactions among all factors in an ICT value creation system in order to manage ICT value. This approach ensures that perception biases are avoided, and that decisions and actions are made based on a correct understanding of the system. This will ensure positive results in creating and managing ICT value.

This finding served as a foundation for proposing an alternative classification of factors influencing ICT value creation process comprising levers, critical catalysts, trends, indicators and buffers. Each group of classified factors influences a choice of strategies for managing an ICT value creation process. By focusing on the levers, managers can identify actions needed to influence the ICT value creation process, and support the achievement of organisational goals and ICT effects. In doing so, managers can use indicators to monitor the success of their efforts. This makes the proposed classification meaningful, relevant and applicable for managing ICT value.

This is the first time that a meaningful classification of the factors influencing an ICT value creation process is reported in the ICT value literature. This will make the alternative classification of factors influencing ICT value reported in this paper of interest to practitioners as well as academics. As this study explored three organisations only, further research is needed to provide more generalised insights. 
The second proposition stated that the same factors will have different functional roles in each of the three ICT value creation systems. However, it was not fully supported. Three factors were found to have the same role in each of the three ICT value creation systems, and additional factors were found to have the same role in two out of the three systems. Due to stark differences among the three organisations that participated in this study, this finding was surprising. It signifies that the identified factors -- IT support, trends in the market and collaboration with customers -- may be of general importance for understanding the process of ICT value creation.

The findings reported in this paper were summarised in an alternative model of the ICT value creation process that reveals the key components that are critical to creating and managing ICT value. The findings presented here can assist managers in focusing their decisions and attention on specific factors in creating ICT value. Understanding the ICT value creation process, in terms of the position of each factor in the system, encourages informed decisions and actions in managing the process of ICT value creation. Furthermore, managers can use the alternative model of ICT value creation to learn why potential value may have been left unrealised (Davern \& Kauffman, 2000). Thus, the ICT value creation system, as conceptualised in this paper, can be instrumental in supporting and improving ICT value and organisational performance.

\section{ACKNOWLEDGEMENTS}

The author would like to thank professor kevin parton and the anonymous referees for their comments on previous drafts of this article.

\section{REFERENCES}

Ackoff, R. L. (1971). Towards a system of systems concepts. Management science, 17(11), 661-671. http://dx.doi.org/10.1287/mnsc.17.11.661

Asan, U., Erhan Bozdağ, C., \& Polat, S. (2004). A fuzzy approach to qualitative cross impact analysis. Omega, 32(6), 443-458. http://dx.doi.org/10.1016/j.omega.2004.02.006

Attewell, P. (1992). Technology diffusion and organizational learning: The case of business computing. Organization Science, 3(1), 1-19. http://dx.doi.org/10.1287/orsc.3.1.1

Bassellier, G., Benbasat, I., \& Reich, B. H. (2003). The influence of business managers' IT competence on championing IT. Information Systems Research, 14(4), 317-336. http://dx.doi.org/10.1287/isre.14.4.317.24899 
Boynton, A. C., Zmud, R. W., \& Jacobs, G. C. (1994). The Influence of IT Management Practice on IT Use in Large Organizations. MIS Quarterly, 18(3), 299-318. http://dx.doi.org/10.2307/249620

Brynjolfsson, E. (1993). The productivity paradox of information technology. Communications of the ACM, 36(12), 66-77. http://dx.doi.org/10.1145/163298.163309

Chan, Y. E., \& Reich, B. H. (2007). IT alignment: what have we learned? Journal of Information Technology, 22(4), 297-315. http://dx.doi.org/10.1057/palgrave.jit.2000109

Davern, M. J., \& Kauffman, R. J. (2000). Discovering potential and realizing value from information technology investments. Journal of Management Information Systems, 16(4), 121-143. http://www.jstor.org/stable/40398459

Davis, F. D. (1989). Perceived usefulness, perceived ease of use, and user acceptance of information technology. MIS Quarterly, 13(3), 319-340. http://dx.doi.org/10.2307/249008

Davis, F. D., Bagozzi, R. P., \& Warshaw, P. R. (1989). User acceptance of computer technology: a comparison of two theoretical models. Management Science, 35(8), 982-1003. http://dx.doi.org/10.1287/mnsc.35.8.982

Delone, W. H., \& McLean, E. R. (2003). The DeLone and McLean model of information systems success: a ten-year update. Journal of Management $\begin{array}{lll}\text { Information } & \text { Systems, } & \text { 9-30. }\end{array}$ http://dx.doi.org/10.1080/07421222.2003.11045748

DeLone, W. H., \& McLean, E. R. (1992). Information systems success: the quest for the dependent variable. Information Systems Research, 3(1), 60-95. http://dx.doi.org/10.1287/isre.3.1.60

Devaraj, S., \& Kohli, R. (2003). Performance impacts of information technology: is actual usage the missing link? Management Science, 49(3), 273-289. http://dx.doi.org/10.1287/mnsc.49.3.273.12736

Fichman, R. G. (1992). Information technology diffusion: a review of empirical research. Paper presented at the ICIS.

Galliers, R. D., Merali, Y., \& Spearing, L. (1994). Coping with information technology \& quest; How British executives perceive the key information systems management issues in the mid-1990s. Journal of Information Technology, 9(3), 223-238. http://dx.doi.org/10.1057/jit.1994.22

Gordon, T. J., \& Hayward, H. (1968). Initial experiments with the cross impact matrix method of forecasting. Futures, 1(2), 100-116. http://dx.doi.org/10.1016/S00163287(68)80003-5 
Gregor, S., Fernandez, W., Holtham, D., Martin, M., Stern, S., Vitale, M., \& Pratt, G. (2004). Achieving Value from ICT: key management strategies. Department of communications, information technology and the arts, ICT research study, Canberra.

Grover, V., \& Kohli, R. (2012). Cocreating IT Value: New Capabilities and Metrics for Multifirm Environments. MIS Quarterly, 36(1), 225-232.

Halecker, B., \& Hartmann, M. (2013). Contribution of systems thinking to business model research and business model innovation. International Journal of Technology Intelligence and Planning, 9(4), 251-270. http://dx.doi.org/10.1504/IJTIP.2013.060756

Helmer, O. (1972). Cross-impact gaming. Futures, 4(2), 149-167. http://dx.doi.org/10.1016/0016-3287(72)90039-0

Jasperson, J. S., Carter, P. E., \& Zmud, R. W. (2005). A comprehensive conceptualization of post-adoptive behaviors associated with information technology enabled work systems. MIS Quarterly, 29(3), 525-557.

Jokela, P., Karlsudd, P., \& Östlund, M. (2008). Theory, Method and Tools for Evaluation Using a Systems-based Approach. Electronic Journal of Information Systems Evaluation, 11(3), 197-212.

Kardaras, D., \& Karakostas, B. (1999). The use of fuzzy cognitive maps to simulate the information systems strategic planning process. Information and Software Technology, 41(4), 197-210. http://dx.doi.org/10.1016/S0950-5849(98)00125-6

Khoumbati, K., Themistocleous, M., \& Irani, Z. (2006). Evaluating the adoption of enterprise application integration in health-care organizations. Journal of Management Information Systems, 22(4), 69-108. http://dx.doi.org/10.2753/MIS0742-1222220404

Kohli, R., \& Devaraj, S. (2003). Measuring information technology payoff: A metaanalysis of structural variables in firm-level empirical research. Information Systems Research, 14(2), 127-145. http://dx.doi.org/10.1287/isre.14.2.127.16019

Kohli, R., \& Grover, V. (2008). Business Value of IT: An Essay on Expanding Research Directions to Keep up with the Times. Journal of the Association for Information Systems, 9(1).

Kumar, R. L. (2004). A framework for assessing the business value of information technology infrastructures. Journal of Management Information Systems, 21(2), 11-32. http://dx.doi.org/10.1080/07421222.2004.11045801

Lamb, R., \& Kling, R. (2003). Reconceptualizing users as social actors in information $\begin{array}{llll}\text { systems } & \text { research. }\end{array}$ http://www.jstor.org/stable/30036529 
McCarthy, I. P. (2003). Technology management-a complex adaptive systems approach. International Journal of Technology Management, 25(8), 728-745. http://dx.doi.org/10.1504/IJTM.2003.003134

Melville, N., Kraemer, K., \& Gurbaxani, V. (2004). Review: information technology and organizational performance: an integrative model of it business value. MIS Quarterly, 28(2), 283-322.

Messerli, P. (2000). Use of sensitivity analysis to evaluate key factors for improving slash-and-burn cultivation systems on the eastern escarpment of Madagascar. Mountain Research and Development, 20(1), 32-41. http://dx.doi.org/10.1659/0276-4741(2000)020[0032:UOSATE]2.0.CO;2

Mithas, S., Tafti, A., Bardhan, I., \& Goh, J. M. (2012). Information technology and firm profitability: mechanisms and empirical evidence. MIS Quarterly, 36(1), 205-224. http://ssrn.com/abstract=1000732

Nevo, S., \& Wade, M. R. (2010). The formation and value of IT-enabled resources: Antecedents and consequences of synergistic relationships. MIS Quarterly, 34(1), 163-183.

Oh, W., \& Pinsonneault, A. (2007). On the assessment of the strategic value of information technologies: conceptual and analytical approaches. MIS Quarterly, 239-265. http://www.jstor.org/stable/25148790

Patel, N. V., \& Hackney, R. (2010). Designing information systems requirements in context: insights from the theory of deferred action. International Journal of Business Information $\quad$ Systems, 6(1), 44-57. http://dx.doi.org/10.1504/IJBIS.2010.034004

Porter, M. E. (2008). The five competitive forces that shape strategy. Harvard Business Review, 86(1), 25-40.

Rajagopal, P. (2002). An innovation - diffusion view of implementation of enterprise resource planning (ERP) systems and development of a research model. Information \& Management, 40(2), 87-114. http://dx.doi.org/10.1016/S03787206(01)00135-5

Rogers, E. M. (1995). Diffusion of innovations (4th ed.). New York: The Free Press.

Sabherwal, R., \& Chan, Y. E. (2001). Alignment between business and IS strategies: a study of prospectors, analyzers, and defenders. Information Systems Research, 12(1), 11-33. http://dx.doi.org/10.1287/isre.12.1.11.9714

Schlange, L. E. (1995). Linking futures research methodologies: an application of systems thinking and metagame analysis to nuclear energy policy issues. Futures, 27(8), 823-838. 
Sharma, R., \& Yetton, P. (2007). The contingent effects of training, technical complexity, and task interdependence on successful information systems implementation. MIS Quarterly, 31(2), 219-238. http://www.jstor.org/stable/25148789

Skoko, H., Ceric, A., \& Chun-yan, H. (2008). ICT adoption models in Chinese SMEs. International Journal of Business Research, 8(4), 161-165.

Soh, C., \& Markus, M. L. (1995). How IT creates business value: a process theory synthesis. Paper presented at the ICIS.

Spencer, J. P., Austin, A., \& Schutte, A. R. (2012). Contributions of dynamic systems theory to cognitive development. Cognitive Development, 27(4), 401-418. http://dx.doi.org/10.1016/j.cogdev.2012.07.006

Tallon, P., Kraemer, K. L., \& Gurbaxani, V. (2000). Executives' perceptions of the business value of information technology: a process-oriented approach. Journal of Management Information Systems, 16(4), 145-173. http://www.jstor.org/stable/40398460

Tallon, P. P., \& Kraemer, K. L. (2006). The development and application of a processoriented" thermometer" of IT business value. Communications of The Association For Information Systems, $17(1), \quad 45$. http://aisel.aisnet.org/cais/vol17/iss1/45

Venkatesh, V., Morris, M. G., Davis, G. B., \& Davis, F. D. (2003). User acceptance of information technology: Toward a unified view. MIS Quarterly, 27(3). 425-478.

Von Bertalanffy, L. (1972). The history and status of general systems theory. Academy of Management Journal, 15(4), 407-426. http://www.jstor.org/stable/30036540

Weill, P., \& Olson, M. H. (1989). An assessment of the contingency theory of management information systems. Journal of Management Information Systems, 6(1), 59-85. http://www.jstor.org/stable/40397905

Zhu, K., \& Kraemer, K. L. (2005). Post-adoption variations in usage and value of ebusiness by organizations: cross-country evidence from the retail industry. Information Systems Research, 16(1), 61-84. http://dx.doi.org/10.1287/isre.1050.0045 
